\title{
THE HEART IN STERNAL DEPRESSION
}

\author{
BY \\ WILLIAM EVANS \\ From the Cardiac Department of the London Hospital \\ Received June 25, 1946
}

The place where the apex beat appears on the chest wall depends as much on the symmetry of the thorax as on the size of the heart. A change in the alignment of the spine, the posterior fulcrum of the thoracic cage, in the form of scoliosis, alters the position of the beat. Local deformity of the ribs which form the walls of the cage will do the same thing. Deformity of the sternum, the anterior fulcrum of the thorax, as a cause of displacement of the apex beat has received less attention. The effects of depression of the sternum (pectus excavatum) on the shape and position of the heart have been studied in sixteen adults examined during the past year.

\section{DESCRIPTION OF CASES}

All sixteen patients had been referred for an explanation of certain signs connected with the heart, with the knowledge that deformity of the chest was present, but without appreciating that the two conditions might be related. In many of them suspicion of heart disease had led to restriction of their physical activities and to a change of design for their future livelihood.

The symptoms that had caused the patients to seek medical advice in the first place were

TABLE I

Summary of Findings in 16 Healthy Subjects with Depressed Sternum

\begin{tabular}{|c|c|c|c|c|c|c|c|c|}
\hline \multirow{3}{*}{$\begin{array}{r}\text { Case } \\
\text { No. }\end{array}$} & \multirow{3}{*}{ Age } & \multirow{3}{*}{$\begin{array}{l}\text { Sternal } \\
\text { depression }\end{array}$} & \multirow{2}{*}{\multicolumn{2}{|c|}{$\begin{array}{l}\text { Antero-posterior } \\
\text { chest measurement } \\
\text { in inches }\end{array}$}} & \multicolumn{4}{|c|}{ Radiological findings in anterior view } \\
\hline & & & & & \multirow{2}{*}{$\begin{array}{l}\text { Translucency } \\
\text { of shadow }\end{array}$} & \multirow{2}{*}{$\begin{array}{c}\text { Apparent } \\
\text { enlargement }\end{array}$} & \multirow[b]{2}{*}{$\begin{array}{l}\text { Outward shift } \\
\text { of left border }\end{array}$} & \multirow[b]{2}{*}{ Scoliosis } \\
\hline & & & \multicolumn{2}{|c|}{$\begin{array}{l}\text { Patient with control } \\
\text { in brackets }\end{array}$} & & & & \\
\hline $\begin{array}{l}1 \\
2\end{array}$ & $\begin{array}{l}36 \\
15\end{array}$ & $\begin{array}{c}\text { Funnel } \\
,,\end{array}$ & $\begin{array}{l}4 \frac{1}{2} \\
5\end{array}$ & $\begin{array}{l}\left(8 \frac{1}{4}\right) \\
(8)\end{array}$ & $\begin{array}{c}\text { Absent } \\
,,\end{array}$ & $\begin{array}{c}\text { Absent } \\
, "\end{array}$ & $\begin{array}{c}\text { Great } \\
,,\end{array}$ & $\begin{array}{c}\text { Effective } \\
\text { Absent }\end{array}$ \\
\hline $\begin{array}{l}3 \\
4 \\
5 \\
6 \\
7\end{array}$ & $\begin{array}{l}57 \\
19 \\
19 \\
29 \\
17\end{array}$ & $\begin{array}{l}\text { Cup } \\
\text {, } \\
\text { ", }\end{array}$ & $\begin{array}{l}5 \frac{1}{4} \\
5 \frac{1}{2} \\
5 \frac{1}{2} \\
5 \frac{1}{2} \\
5 \frac{1}{2}\end{array}$ & $\begin{array}{l}\left(8 \frac{1}{2}\right) \\
(8) \\
\left(7 \frac{1}{2}\right) \\
\left(8 \frac{1}{2}\right) \\
\left(7 \frac{1}{4}\right)\end{array}$ & $\begin{array}{l}\text { Obvious } \\
\text {," } \\
, \\
, \\
,\end{array}$ & $\begin{array}{c}\text { Moderate } \\
, ", \\
\text {," } \\
\text { Moderate to } \\
\text { slight }\end{array}$ & $\begin{array}{c}\text { Moderate } \\
\text {," }\end{array}$ & $\begin{array}{l}\text { "’ } \\
\text { Incidental } \\
\text { Effective } \\
\text { Absent }\end{array}$ \\
\hline $\begin{array}{r}8 \\
9 \\
10\end{array}$ & $\begin{array}{l}17 \\
23 \\
36\end{array}$ & ", & $\begin{array}{l}5 \frac{1}{2} \\
5 \frac{1}{2} \\
5 \frac{3}{4}\end{array}$ & $\begin{array}{l}\left(8 \frac{1}{2}\right) \\
(7) \\
\left(8 \frac{1}{2}\right)\end{array}$ & $\begin{array}{l}\text { ", } \\
\text {," }\end{array}$ & ", & Considerable & $\begin{array}{c}\text { Incidental } \\
\text { Effective } \\
\quad,,\end{array}$ \\
\hline $\begin{array}{l}11 \\
12 \\
13 \\
14 \\
15 \\
16\end{array}$ & $\begin{array}{l}15 \\
19 \\
19 \\
19 \\
19 \\
31\end{array}$ & $\begin{array}{c}\text { Saucer } \\
\text {, } \\
, \\
, \\
,\end{array}$ & $\begin{array}{l}6 \\
6 \\
6 \\
6 \\
6 \frac{1}{4} \\
6 \frac{1}{4}\end{array}$ & $\begin{array}{l}(7) \\
(7) \\
\left(7 \frac{1}{2}\right) \\
\left(7 \frac{1}{2}\right) \\
(7) \\
(8)\end{array}$ & $\begin{array}{l}\text { Slight } \\
\text {," } \\
\text {," } \\
\text {," }\end{array}$ & 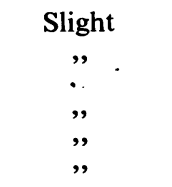 & $\begin{array}{c}\text { Moderate } \\
\text { ", } \\
\text { ", } \\
\text { Slight }\end{array}$ & $\begin{array}{c}\text { Incidental } \\
\text { Absent } \\
\text {, } \\
\text { Incidental }\end{array}$ \\
\hline
\end{tabular}

Note. In addition, the apex beat was displaced outwards in every case and a systolic murmur was present. In the anterior view the pulmonary artery was prominent on cardioscopy in the funnel and cup depression, but not in the saucer variety. In the left oblique view the heart shadow was normal or smaller in size, and in each case it extended on to the spine. 


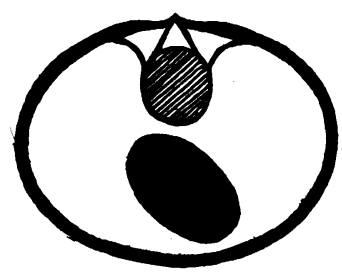

Normal

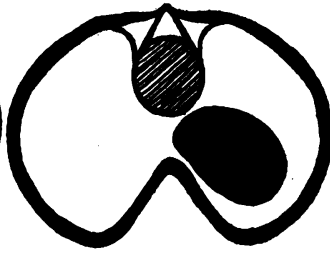

Funnel Depression

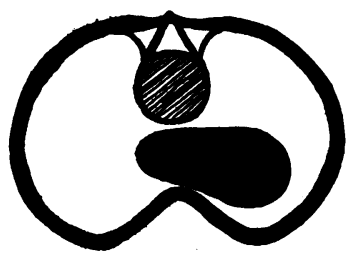

Cup Depression

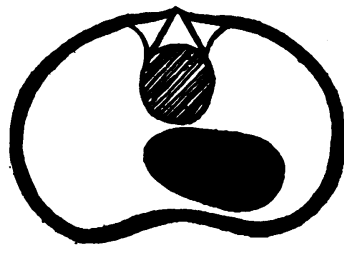

Saucer Depression

FIG. 1.-Diagramatic representation of the position of the heart in the three kinds of depression of the sternum.

diverse and never the outcome of cardiac embarrassment. In none was there heart failure such as has been attributed to gross deformity of the spine (Coombs, 1930). The symptoms were irrelevant to the condition and were of a general kind such as palpitation, giddiness, tiredness, and lancing pain in the left chest. Of greater importance were the restrictions imposed on the patients, even when symptom-free, because of a routine medical examination. Rheumatic heart disease had been diagnosed in five cases, which were advised to submit to regular medical supervision. Four cases had been relegated to the low health categories of Grade III or IV by Medical Recruiting Boards. Termination of pregnancy had been advised for one. Long periods in bed and absence from her calling as a teacher had been enforced on two occasions in another, aged 57 ; while another, a boy of 19 , had been compelled by his medical advisers to discontinue his studies as a medical student; and later was placed in Grade IV

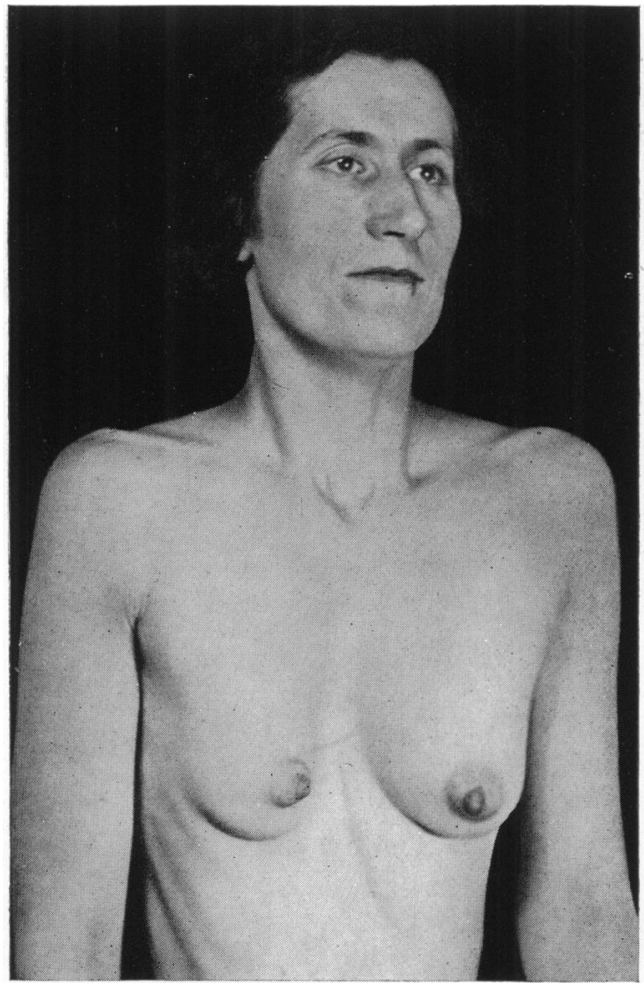

Fig. 2.-Funnel depression in Case 1. Anteroposterior (A-P) measurement of $4 \frac{1}{4}$ inches against $8 \frac{1}{4}$ inches in control.

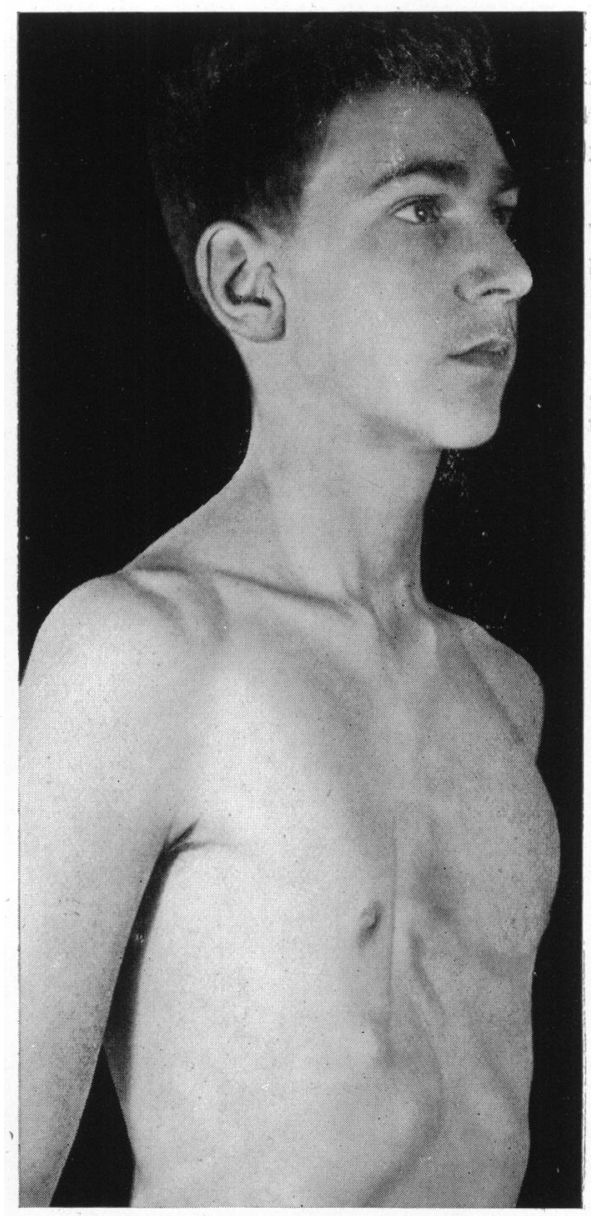

Fig. 3.-Funnel depression in Case 2. A-P measurement of 5 inches against 8 inches in control. 
by three different Medical Boards after an examination that was amplified by a radiologist's report to the effect that there was great enlargement of the heart.

The physical signs relate to the sternal deformity and to the altered shape and position of the heart; they have been summarized in Table I.

The sternal depression. It has been conventional to refer to this deformity of the lower end of the sternum as funnel depression, but when the present series was examined it became evident that the effects on the heart depended directly on the extent of the backward bulge of the sternum. Adopting the same simile, three types may be described, the funnel, the cup, and the saucer depression, according to the depth of the sternal pit (Fig. 1). Thus, the funnel type is deep and usually narrow at the apex (Fig. 2 and 3), and the cup variety is moderately deep and usually rounded at the apex, while the saucer type is a shallower and wider depression. The antero-posterior measurement of the chest in the two cases with funnel depression was $4 \frac{1}{2}$ and 5 inches respectively; in eight cases of cup deformity it varied from $5 \frac{1}{4}$ to $53 / 4$ inches, and in the six cases with saucer depression it was 6 or $61 / 4$ inches. The same measurement for the control series of 16 healthy subjects was never less than 7 inches and the average was $73 / 4$ inches (Table I). The lateral measurement was unaffected by the sternal deformity and the average of 10 inches was the same for the control series.

The apex beat. This was displaced to the left in all 16 cases; this effect was obvious in the six instances of saucer depression, but it was greater in the ten cases with either cup or funnel depression (Fig. 4 and 5), and in these it often appeared beyond the anterior axillary line. Although scoliosis was present in nine, it only contributed to the displacement in four and even in these in only a small way. In the two cases showing the severe or funnel form of depression the shift of the apex beat had resulted from the escape cf the heart to the left away from the grasp of the jaws formed by the sternal bulge and the spine. In the 14 cases with cup or saucer depression the right border of the heart had maintained its normal relationship to the spine, although sometimes it was lifted a little, so that the outward shift of the left

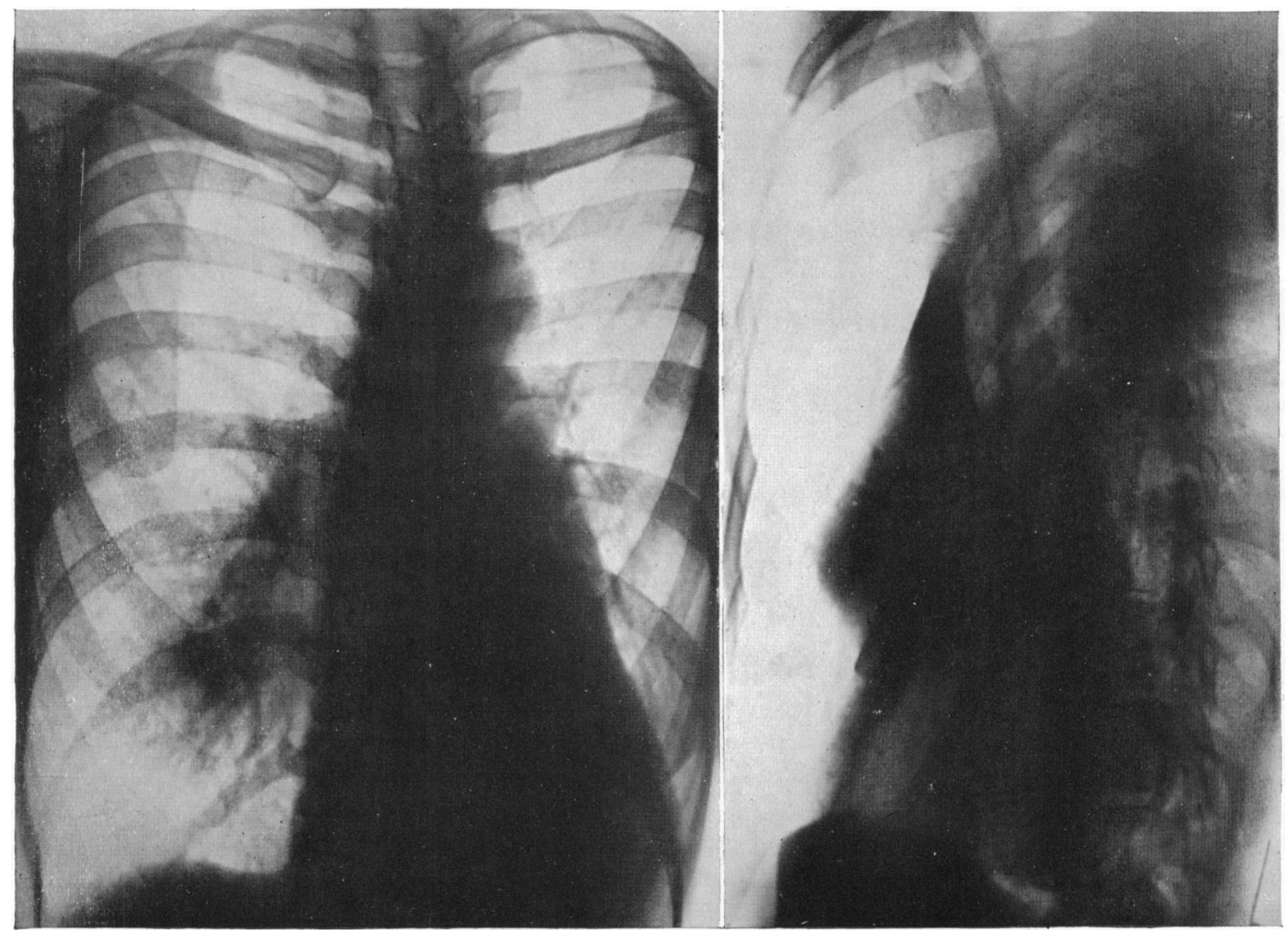

FIG. 4.-Anterior and left (II) oblique teleradiograms in Case 1 with funnel depression. The heart is displaced backwards and to the left. 


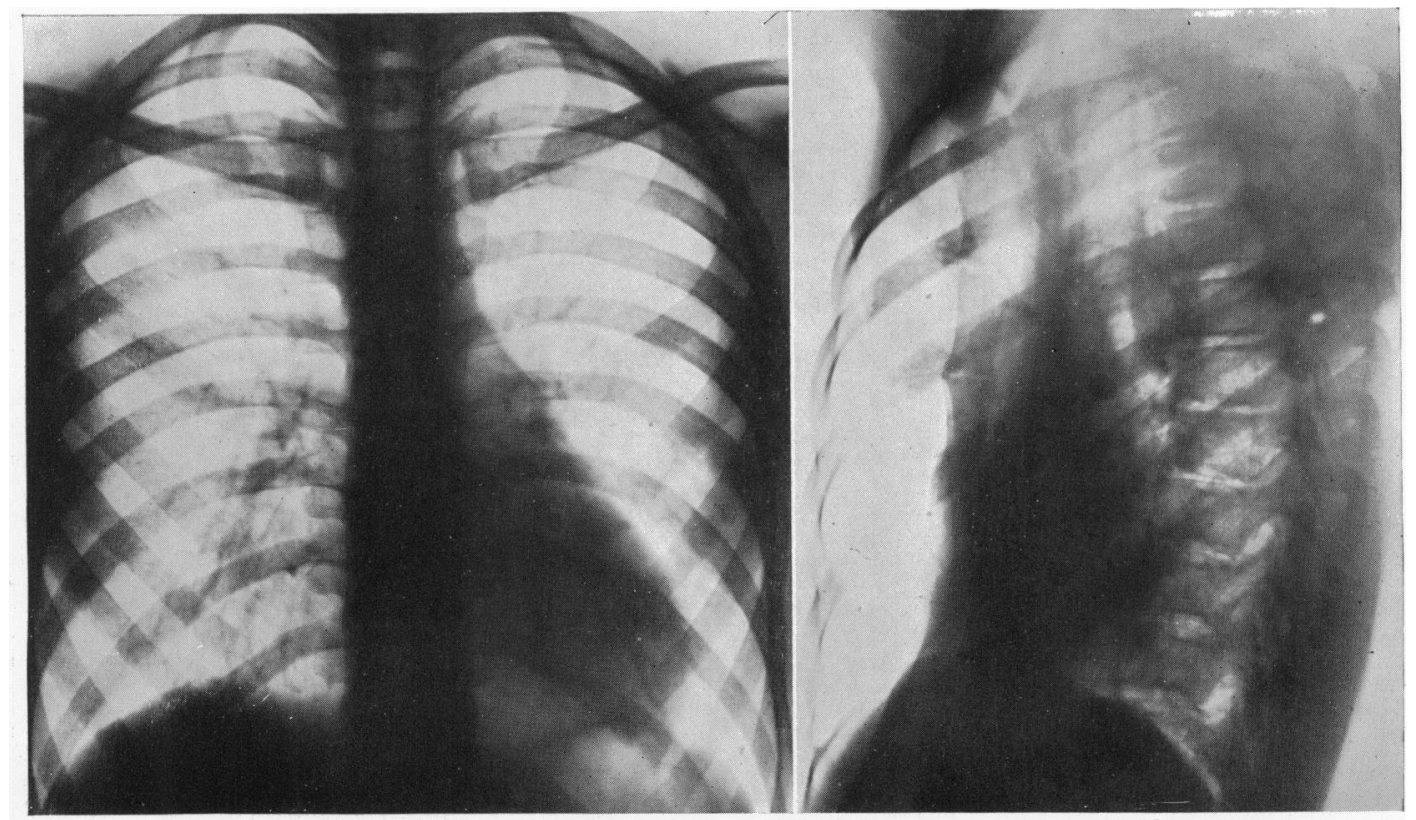

FIG. 5.-Anterior and left oblique teleradiograms in Case 2 with funnel depression. The heart is displaced bodily to the left.

border and the apex beat was the outcome of flattening or compression of the heart within the jaws of the sterno-spinal vice.

Where physical activities had been limited on medical advice, displacement of the apex beat had been accepted as evidence of cardiac enlargement and as one reason for imposing the unjustified restrictions.

The heart murmur. A systolic murmur, heard best at the left edge of the depression, was present in all. It was sometimes moderately loud; in three cases it was short and accompanied by splitting of the first heart sound which formed the chief auscultatory sign. The presence of the murmur had always seemed to add significance to the displaced apex beat and had increased the suspicion that organic heart disease had produced cardiac enlargement. Actually the murmur was of the innocent kind and was situated in mid-systole; it might have been produced by the impact of the heart on the sternal bulge, for the murmur was louder in the cup depression than in the saucer variety.

Radiological findings. The wider application of cardioscopy (radiological examination of the heart) in the investigation of patients suspected of heart disease, has in the meantime tended to confirm rather than remove the invalidism imposed after clinical examination of subjects showing depression of the sternum. This has arisen from a failure to discern that the enlargement of the cardiac silhouette in such cases results from a change in the shape of the heart and not from an alteration in its size.

In the two cases of funnel depression (Fig. 2 and 3) the heart was displaced bodily to the left (Fig. 4 and 5), and without changing the shape or size of the heart shadow in either the anterior or oblique views.

In the eight cases of cup depression (Fig. 6 to 9) there was enlargement of the anterior cardiac silhouette with prominence of the pulmonary arc. The enlargement was moderate in four (Fig. 10 and 11), and slight in the other four (Fig. 12). That such enlargement was apparent and not real was confirmed in the oblique views where the heart shadow was normal in size or sometimes seemed small.

In the six cases of saucer depression (see Fig. 15, p. 169), enlargement of the heart shadow in the anterior view was present but slight (Fig. 13), yet the condition is no less important on that account. Indeed, since some of the other signs of sternal depression are less conspicuous in this variety, the recognition of the effects of saucer depression needs even greater 


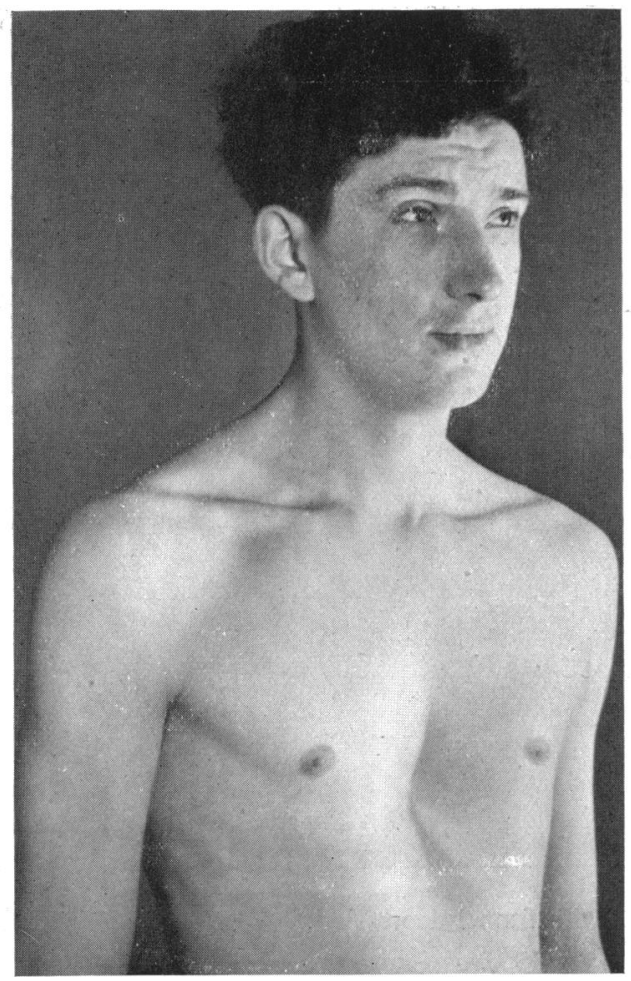

Fig. 6.-Cup depression in Case 4. A-P measurement of $5 \frac{1}{2}$ inches against 8 inches in control.

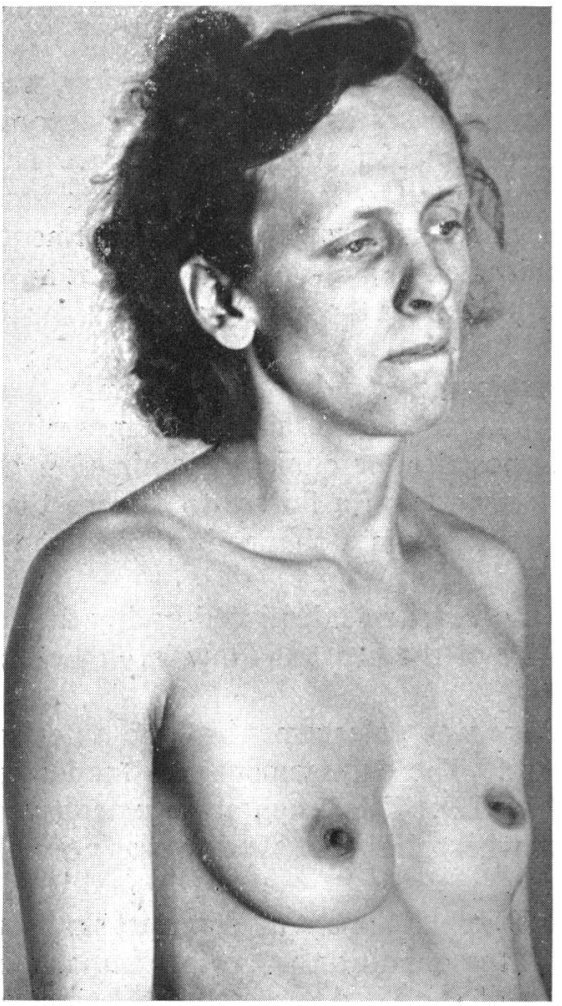

Fig. 8.-Cup depression in Case 6. A-P measurement of $5 \frac{1}{2}$ inches against $8 \frac{1}{2}$ inches in control.

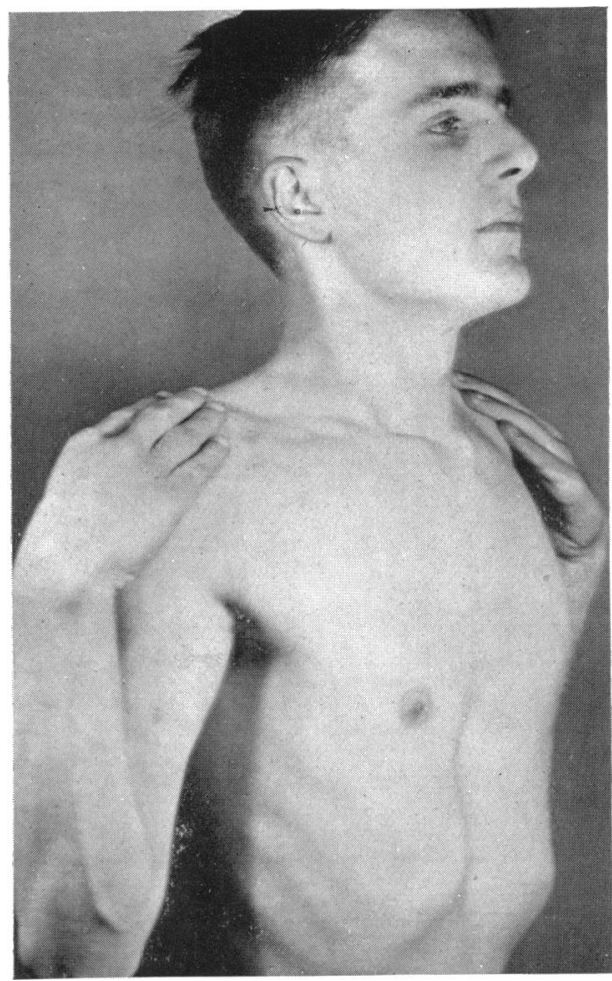

FIG. 7.-Cup depression in Case 5. A-P measurement of $5 \frac{1}{2}$ inches against $7 \frac{1}{2}$ inches in control.

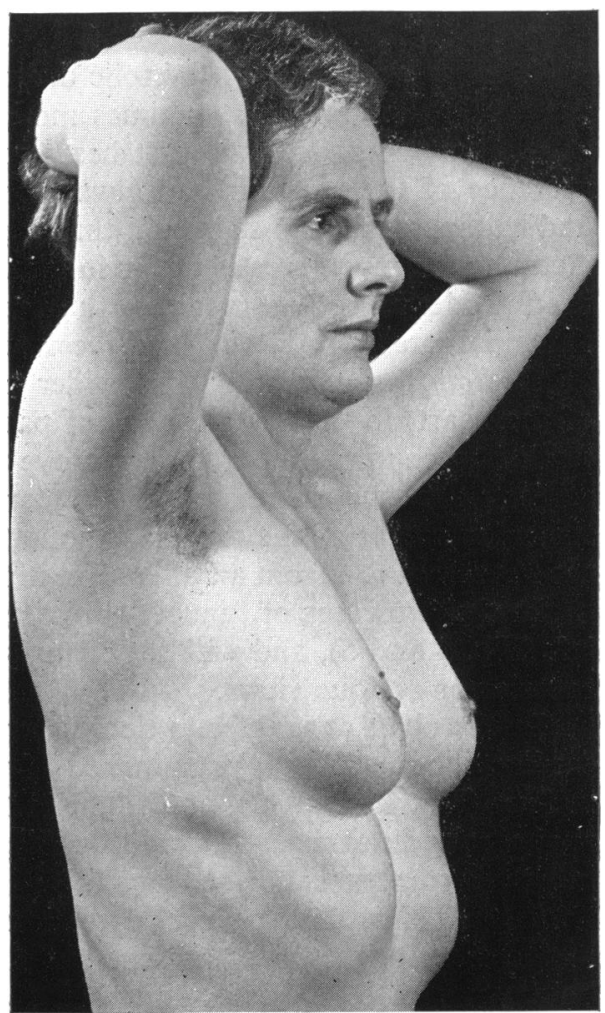

FIG. 9.-Cup depression in Case 10. A-P measurement of $5 \frac{3}{4}$ inches against $8 \frac{1}{2}$ inches in control. 


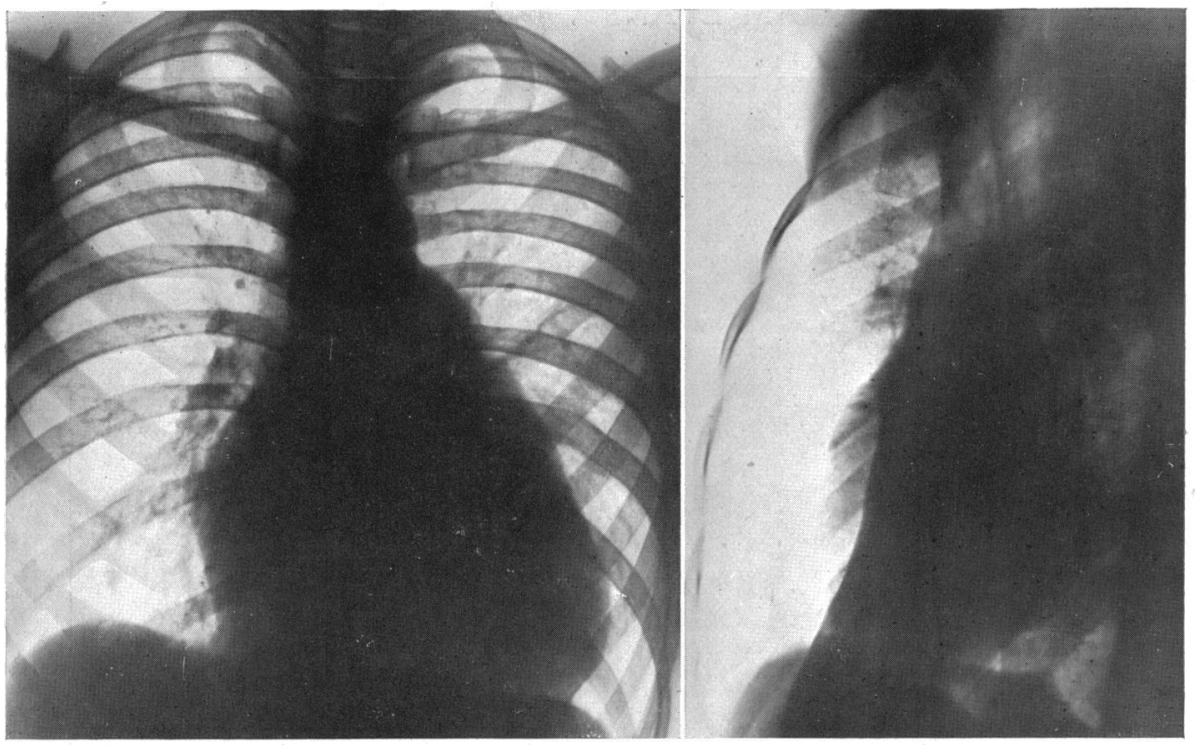

Fig. 10.-Anterior and left oblique teleradiograms in Case 4 with cup depression. The heart shadow is enlarged and the pulmonary arc is prominent in the anterior view, but the heart is normal and moved backwards in the left oblique.
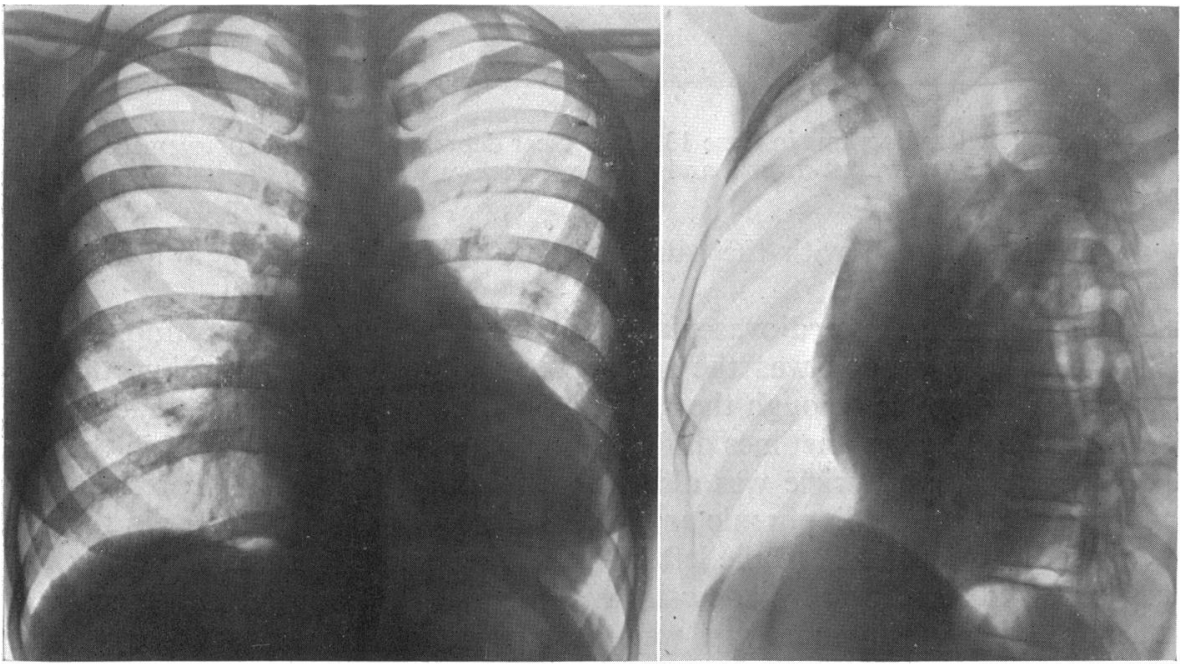

FIG. 11.-Anterior and left oblique teleradiograms in Case 10 with cup depression. The heart shadow is enlarged in the anterior view, but normal and displaced backwards in the left oblique.

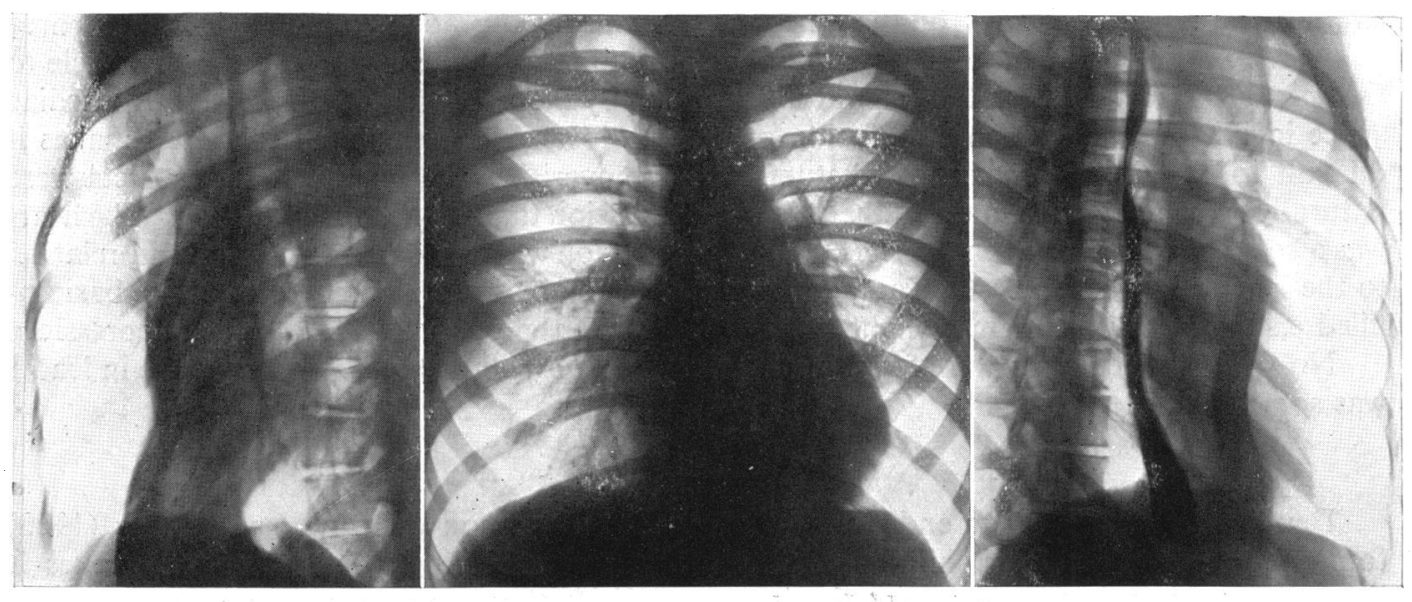

FIG. 12.-Anterior and left and right oblique teleradiograms in Case 5 with cup depression. The heart shadow is moderately enlarged in the anterior view but normal in the obliques. 


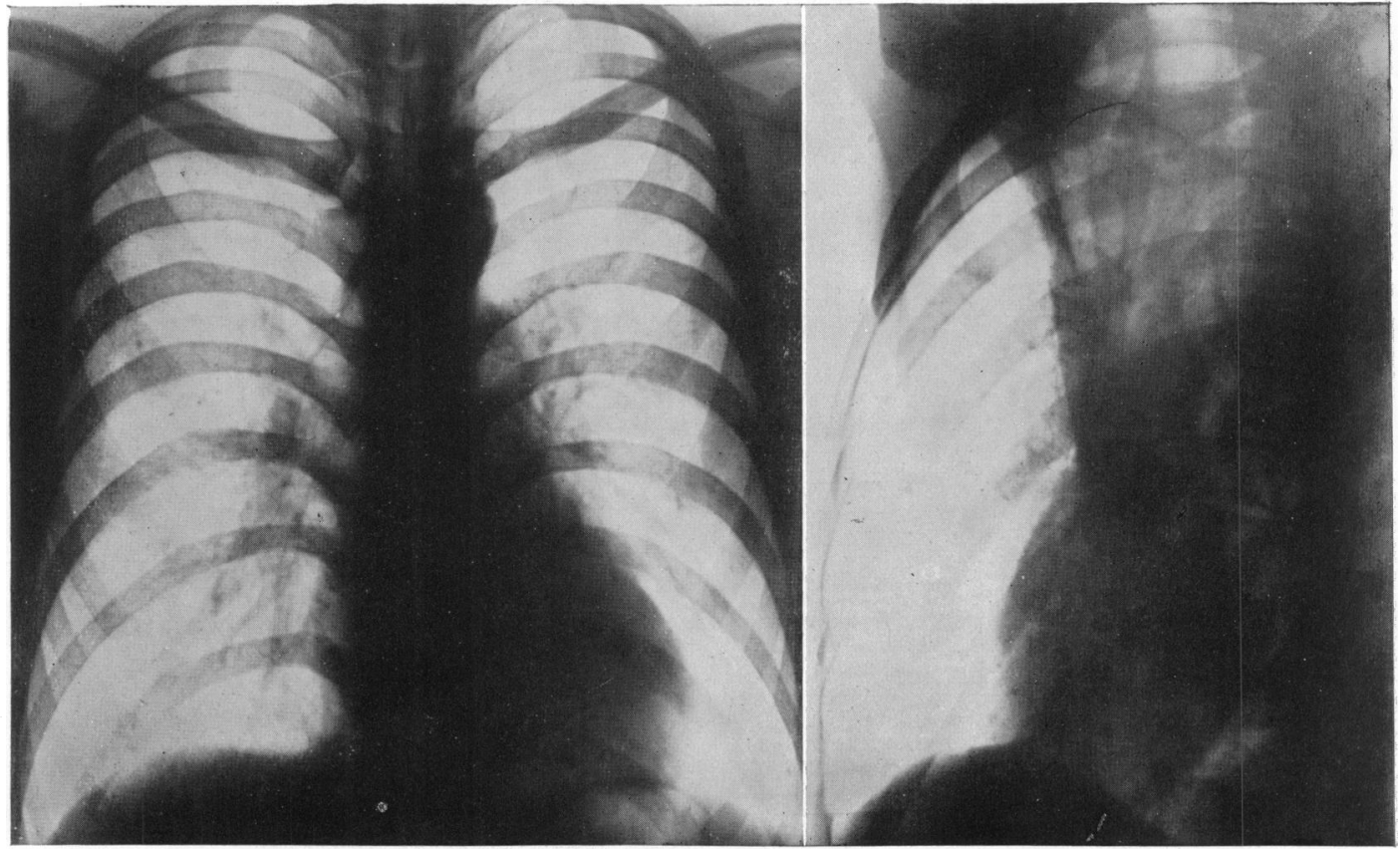

Fig. 13.-Anterior and left oblique teleradiograms in Case 13 with saucer depression. Slight enlargement of the heart shadow in the anterior view, but normal and displaced backwards in the left oblique.

emphasis. As with cup depression so with the saucer variety the heart shadow appeared normal in size in the oblique views.

In addition to the enlargement of the cardiovascular silhouette in the anterior view another characteristic feature during cardioscopy was the transparency of the shadow. Thus the spine and ribs were plainly discernible through the heart, and so light was the heart shadow to the right of the sternum that it was sometimes difficult to make out on screening alone the limits of the right border; the right auricle was also often lifted by the sternal depression below causing widening of the right cardiophrenic angle; emphysema was not a factor in the production of such changes. Immediately to the left of the spine a band-like area especially lacked the customary density of the heart shadow in this position. Naturally such transparency was absent in the funnel depression, and was more obvious in the cup depression than in the saucer variety. In the left (II) oblique position, apart from the size of the heart appearing normal or even smaller, a characteristic finding was its displacement backwards to overlap the adjacent bodies of the vertebræ. Similarly the aortic window (the light area below the aortic arch) was constricted by the approximation of the cardiovascular pedicle to the spine. This trespass on the clear areas provided by the aortic window and the retrocardiacspace in this view, caused by the fusion of the cardiovascular and spinal shadows, makes it difficult to identify the separate structures and impoverishes the picture. Such effects were naturally more noticeable in the funnel and cup depression than in the saucer variety. The heart was also normal or narrow in the right (I) oblique position where the bony deformity in relation to the heart was seen to best advantage. There was no abnormal displacement of the bariumfilled œsophagus apart from a slight shift to the left in the two cases with funnel depression.

No significant changes were found in the electrocardiogram except that the S wave in lead I was sometimes deep (Fig. 14).

\section{Discussion}

Depression of the lower end of the sternum is a common deformity and Lang (1928) found it in 3.5 per cent of children in the first year of schooling. This incidence makes it important to recognize and accept the innocent effects that the deformity may produce on the heart so as to guard against misinterpreting these for the more sinister signs connected 

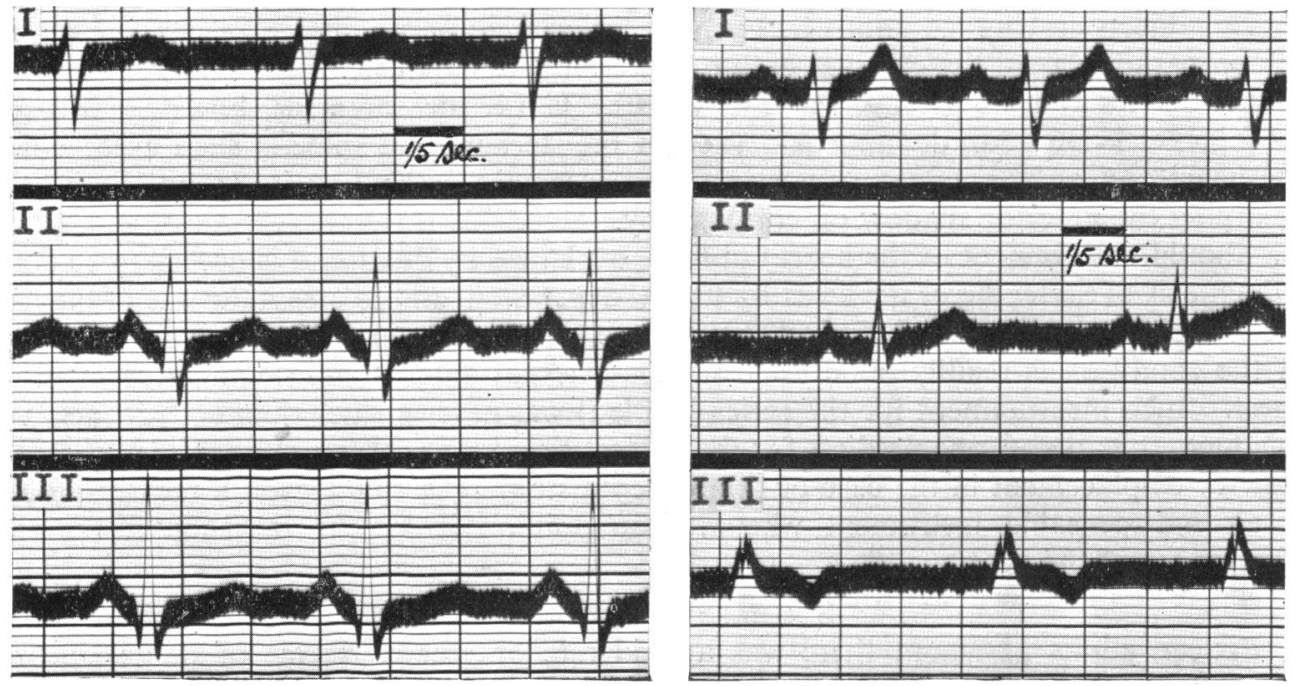

FIG. 14.-The electrocardiogram from Cases 1 and 7 showing deep $S$ wave in lead I.

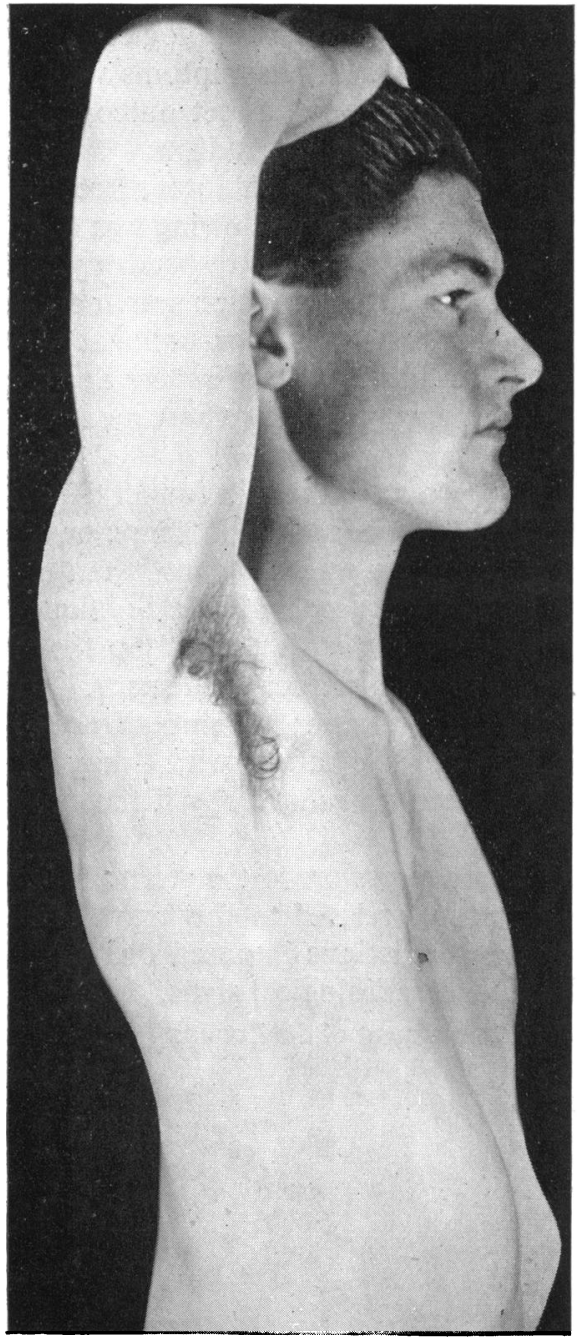

FIG. 15.-Saucer depression in Case 13. A-P measurement of 6 inches against $7 \frac{1}{2}$ inches in control. with true cardiac enlargement and the conditions that give rise to it. There are many factors said to play a part in the evolution of this sternal deformity, such as abnormal length of the ribs (Flesch, 1873), occupations like cobbling (Laennec, 1819), intra-uterine arrest of the development of the sternum (Ebstein, 1882), and post-natal abnormal development in a child of slender build arising from faulty posture (Kuhns, 1931). Here there was no evidence that any had resulted from congenital maldevelopment, and in all it appeared in early childhood when it might have been the outcome of a disturbance in the mechanism of respiration.

Greatest interest lies with the changes in the heart shadow on cardioscopy. Cardiac hypertrophy was reported by Bein (1912), Frühwald (1913), and Findlay (1921), while Roesler (1943) spoke of circulatory embarrassment. No such effects were observed in my series; the cardiac silhouette was always enlarged in the anterior view in both the cup and saucer depression, but the heart was merely altered in shape and not in size, for it was normal and sometimes small in the oblique views. The explanation of the irregular findings on cardioscopy comes from a study of the thoracic measurements in sternal depression. The antero-posterior measurement of the heart in a series of necropsies on adults was about 3 inches, and the thickness of the sternum, vertebral column, and the soft tissue covering them was about $33 / 4$ inches. Thus when the external antero-posterior measurement of the chest is $63 / 4$ inches the heart assumes its natural contour and is not subject to external pressure. 
In 16 subjects serving as control cases for the present series, being of the same age and of comparable build, the external antero-posterior measurement of the chest was never less than 7 inches and the average was $73 / 4$ inches. If this measurement, however, is less than $61 / 2$ inches in an adult the approximation of the sternum and spine is such as to compress the heart and reduce its antero-posterior measurement, extending its lateral limits and so enlarging the anterior shadow on cardioscopy.

Should enlargement of the heart fail to be explained by disease, it is necessary to entertain a diagnosis of flattening of the heart by sternal depression, and to assess the size of the heart in the left oblique position, observing at the same time its relation to the spine. Confirmation of the condition is readily obtained from the external antero-posterior measurement of the chest. Such measurement for the series (Table I) was never greater than $61 / 4$ inches, so that this figure or a lesser one predicts for the subject a widened cardiac silhouette in the anterior view or displacement in the case of funnel depression. For this reason a measuring calliper is an indispensable instrument whenever an opinion is sought on such a radiological appearance of the heart.

\section{Summary AND Conclusions}

Sixteen adults in whom there was a moderate or greater degree of depression of the sternum were examined especially for its effect on the heart. The association of a displaced apex beat and a systolic murmur with the deformity had led to a restriction of physical activities in every case; this invalidism had been enforced more rigidly whenever radiological examination had been added, because it had shown a big heart shadow. The symptoms were never once the result of heart enlargement or embarrassment, but were the direct outcome of the physical inactivity or mental anxiety resulting from the unwarranted invalidism.

According to the depth of the depression the cases were separated into three groups. Two cases belonged to the first group of funnel depression, where the hollowing was deep and the external antero-posterior chest measurement was $4 \frac{1}{2}$ and 5 inches respectively. Eight cases belonged to the second group of cup depression, where the receission was moderately deep and its apex more rounded; the external antero-posterior chest measurement in these cases varied from $51 / 4$ to $53 / 4$ inches. Six cases formed the third group of saucer depression, where the dip was shallower and wider and the external antero-posterior chest measurement was 6 or $61 / 4$ inches.

The radiological findings were characteristic for each group. Thus, in funnel depression the heart was displaced bodily to the left of the spine and was unchanged in shape or in size. In the cup depression the cardiac silhouette in the anterior view was less dense than normal and was moderately enlarged with prominence of the pulmonary arc; in the left oblique view the heart shadow was normal or small, and was displaced backwards to overlap the spine, thereby obliterating the clear areas of the aortic window and the retrocardiac space. Similar effects, although less in degree, were observed in the saucer depression; the importance of this last group lies in the less obvious chest deformity giving rise to changes which may lead to the erroneous interpretation of the enlarged cardiac area seen on radioscopy if the effects of this saucer depression are not known.

It needs final emphasis that none of the 16 cases with depression of the sternum showed actual enlargement of the heart, nor suffered from symptoms related to the heart. Indeed, they were all healthy and were handicapped only by the restrictions imposed on them by a medical examination that had misinterpreted the clinical and radiological signs.

I wish to thank Dr. John Parkinson, Physician to the Cardiac Department of the London Hospital, for his helpful criticism of this paper.

Bein, G. (1912). Ziegler Beitr. path. Anat., 52, 567.

\section{REFERENCES}

Coombs, C. F. (1930). Brit. J. Surg. 18, 326.

Ebstein, W. (1882). Deutsch. Arch. klin. Med., 30, 411.

Findlay, F. G. (1921). Connecticut med. Ass., 11, 10.

Flesch, M. (1873). Virchows Arch. path. Anat., 57, 289.

Frühwald, H. C. (1913). Ziegler Beitr. path. Anat., 13, 56.

Kaumheimer, L. (1919). Z. orthop. Chir., 39, 68.

Kuhns, J. G. (1931). New Eng. Jour. Med., 204, 1077.

Lang, K. (1928). Klin. Wschr., 7, 1283.

Roesler, H. (1943). Clinical Roentgenology of the Cardiovascular system. 2nd Ed. Springfield, U.S.A. 